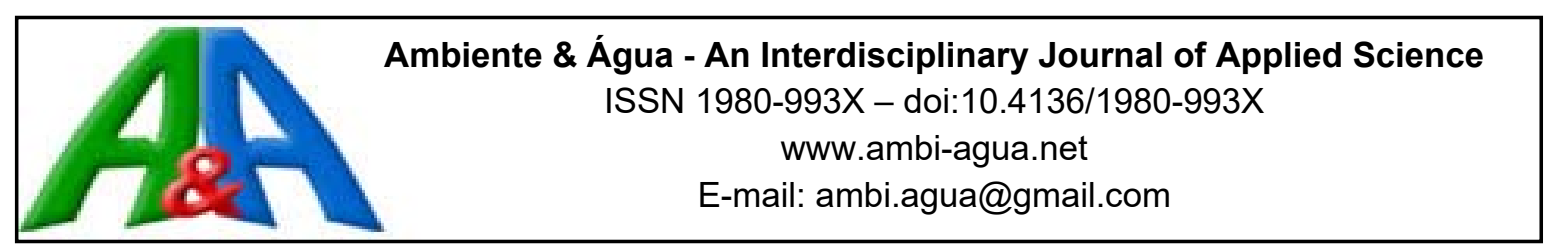

\title{
Gerenciamento de áreas contaminadas por postos de combustíveis em Cuiabá, Mato Grosso, Brasil
}

\author{
doi:10.4136/ambi-agua.1872 \\ Received: 01 Mar. 2016; Accepted: 30 Jan. 2017

\section{Suzy Darley de Lima; Andrea Ferreira de Oliveira; Rossean Golin; Danila Soares Caixeta; Zoraidy Marques de Lima; Eduardo Beraldo de Morais*} \\ Universidade Federal de Mato Grosso (UFMT), Cuiabá, MT, Brasil \\ Departamento de Engenharia Sanitária e Ambiental \\ *Autor correspondente: e-mail: beraldo_morais@yahoo.com.br, \\ suzyd.lima@gmail.com, oliveira27andrea@gmail.com, golin.rossean@gmail.com, \\ danilacaixeta@gmail.com, zoraidy@terra.com.br
}

\section{RESUMO}

A comercialização de combustíveis derivados de petróleo é uma atividade potencialmente poluidora. Tal impacto ocorre principalmente devido a acidentes no transporte com caminhão tanque e vazamentos nos tanques de armazenamento subterrâneo dos postos de combustíveis. O gerenciamento de áreas contaminadas tem o objetivo de reduzir os riscos à saúde humana por meio do conhecimento das características do local contaminado e dos impactos causados pelos contaminantes, proporcionando assim auxílio à tomada de decisão quanto às formas de intervenção mais adequadas. Neste trabalho, por meio da análise dos processos de licenciamento ambiental dos postos de combustíveis de Cuiabá, MT, Brasil, foi possível apresentar um panorama dos postos com algum tipo de contaminação ambiental, já que a investigação de passivos é obrigatória durante esse licenciamento. De 136 processos de licenciamento analisados, constatou-se que em 17 os laudos ambientais apresentaram algum tipo de contaminação no solo e/ou água subterrânea. Os principais contaminantes encontrados foram Benzeno, Tolueno, Etilbenzeno e Xilenos Totais (BTEX) e Hidrocarbonetos Policíclicos Aromáticos (HPA's). Em oito postos foram aplicadas as seguintes técnicas de remediação: três de atenuação natural, três de extração multifásica e três de bombeamento. Ressalta-se que nos nove postos restantes, não foi encontrada informação sobre a aplicação de técnicas de remediação. Destaca-se a necessidade do órgão ambiental estadual tornar pública as informações sobre as áreas contaminadas presentes não somente em Cuiabá, mas em todo o Estado. Segundo a Resolução CONAMA 420/2009 esta é uma obrigação do órgão ambiental para que o gerenciamento das áreas contaminadas possa ser efetivo. É importante também o Estado estabelecer políticas relativas à gestão das áreas contaminadas com legislações específicas ao tema, assim como alguns Estados já tem feito.

Palavras-chave: água subterrânea, hidrocarbonetos, licenciamento ambiental, passivo ambiental. 


\title{
Management of contaminated areas by gas stations in Cuiabá, Mato Grosso, Brazil
}

\begin{abstract}
The commercialization of petroleum-based fuels is a potentially polluting activity. Environmental impacts are mainly due to tanker truck accidents and leaking underground storage tanks of gas stations. The management of contaminated sites aims to reduce risks to human health and environment through measures that provide knowledge regarding the characteristics of contaminated site and the impacts of contaminants, thus allowing the most appropriate intervention to be determined. This paper analyzed the environmental licensing process of the Cuiaba-MT gas stations in order to present an overview of the gas stations responsible for some type of environmental contamination, since the investigation of liabilities is required for this license. One hundred and thirty-six licensing processes were analyzed, and it was found that 17 of these reported some type of contamination in soil and/or groundwater. The main contaminants were Benzene, Toluene, Ethylbenzene and Xylenes (BTEX) and Polycyclic Aromatic Hydrocarbons (PAHs). The following remediation techniques were applied: three cases of natural attenuation, three of multiphase extraction and three of pumping. This highlights the necessity for the State Environment Agency to make available information about contaminated areas not only in Cuiabá but throughout the State. According to CONAMA Resolution 420/2009, this is an obligation of the environmental agency for the management of contaminated areas to be effective. It is also important that the Mato Grosso State establish public policies for the management of contaminated areas, with legislation specific to the issue, as some other Brazilian states have done.
\end{abstract}

Keywords: environmental liability, environmental licensing, groundwater, hydrocarbons.

\section{INTRODUÇÃ̃O}

De acordo com a Agência Nacional de Petróleo (ANP), o Brasil tem apresentado acréscimo na instalação de postos revendedores de combustíveis automotivos, passando de 36.730 (2008) para 39.763 (2014) postos instalados, mantendo-se na quinta posição no ranking de maiores consumidores de petróleo (ANP, 2015).

Da mesma forma, verifica-se o aumento da quantidade de áreas contaminadas decorrentes desse tipo de atividade, como consta nos inventários efetuados pelos órgãos ambientais de alguns Estados brasileiros, como São Paulo e Minas Gerais, que possuem há mais tempo o gerenciamento de áreas contaminadas (Minas Gerais, 2015; CETESB, 2014). Este aumento está associado à publicação da Resolução CONAMA no 273/2000 (Brasil, 2000) que dentre as diretrizes instituídas, estabeleceu a obrigatoriedade da investigação de passivos ambientais para o licenciamento ambiental de postos de combustíveis e serviços.

Os passos para o gerenciamento ambiental de áreas contaminadas são descritos na Resolução CONAMA n ${ }^{\circ}$ 420/2009 (Brasil, 2009) que determina critérios e valores orientadores de referência de qualidade, de prevenção e de investigação do solo e valores de investigação para águas subterrâneas. A Resolução cita que na ocorrência comprovada de substâncias químicas que possam causar risco à saúde humana e ao meio ambiente, ações específicas para a proteção da população exposta devem ser desenvolvidas por órgãos competentes.

As áreas contaminadas têm sido uma constante preocupação para os gestores públicos, uma prova disso é o Estado de São Paulo, que foi pioneiro no levantamento e cadastramento dessas áreas. Desde 2002, a Companhia Ambiental do Estado de São Paulo (CETESB), órgão 
vinculado à Secretaria Estadual do Meio Ambiente, tem apresentado em forma de inventário uma lista com as áreas contaminadas, informando qual o setor que mais tem contribuído para contaminação do solo e das águas subterrâneas. Segundo esse relatório, a principal atividade responsável pelas áreas contaminadas no Estado são os postos de combustíveis com 3.825 registros (74\%), ficando bem a frente das demais atividades como: indústrias (17\%), comerciais (5\%), instalações para destinação de resíduos (3\%) e casos de acidentes, agricultura e fonte de contaminação de origem desconhecida (1\%) (CETESB, 2014).

Outros Estados também têm adotado essa ferramenta. Em 2007, Minas Gerais publicou a primeira lista de suas áreas contaminadas, que é atualizada anualmente pela Fundação Estadual do Meio Ambiente (FEAM). Atualmente, a cidade de Belo Horizonte possui 199 áreas contaminadas enquanto que nas demais regiões do Estado, 418 áreas possuem contaminação. As principais atividades econômicas associadas às áreas contaminadas são postos de combustíveis $(73 \%)$, indústria $(15 \%)$, ferrovias $(7 \%)$, mineradoras $(2 \%)$ e outras $(4 \%)$ (Minas Gerais, 2015).

O Estado do Rio de Janeiro após sancionar em dezembro de 2012 a Resolução CONEMA $n^{\circ} 44$ (Rio de Janeiro, 2012) que dispõe sobre a obrigatoriedade da identificação de eventual contaminação ambiental do solo e das águas subterrâneas, publicou uma lista e um mapa das áreas contaminadas e reabilitadas, por meio do Instituto Estadual do Ambiente (INEA). Ao todo são 328 áreas afetadas por diversos tipos de poluentes e os postos de combustíveis são os principais responsáveis por essas contaminações (58\%) (Rio de Janeiro, 2015).

O maior interesse em fazer um levantamento das áreas contaminadas por combustíveis derivados de petróleo surgiu devido à complexidade, toxicidade e mobilidade no ambiente dos compostos monoaromáticos do grupo BTEX (Benzeno, Tolueno, Etilbenzeno e Xileno Totais), presentes nos combustíveis. Segundo Andrade et al. (2010), compostos como os BTEX são tóxicos tanto ao meio ambiente como ao ser humano, em que atuam como depressores do sistema nervoso central e apresentam toxicidade crônica mais significativa que os hidrocarbonetos alifáticos (também presentes no petróleo e derivados), mesmo em concentrações da ordem de $\mu \mathrm{g} \mathrm{\textrm {L } ^ { - 1 }}$.

Uma vez constatada que a comercialização de combustíveis automotivos é a principal atividade responsável pela contaminação de solos e águas subterrâneas nos Estados citados, essa merece total atenção dos demais órgãos ambientais dos outros entes federativos. A Secretaria de Estado de Meio Ambiente de Mato Grosso (SEMA/MT) não possui um inventário das áreas contaminadas do Estado, ficando o alerta para a necessidade da elaboração do documento, pois por meio dele será possível a tomada de decisão mais eficaz para a minimização dos impactos. Segundo o último levantamento da ANP, o Estado de Mato Grosso tem 1.027 postos revendedores de combustíveis automotivos, ficando classificado como o $12^{\circ}$ Estado com maior quantidade de postos instalados no país (ANP, 2015).

O presente estudo tem como finalidade apresentar um panorama dos postos de combustíveis responsáveis por algum tipo de contaminação do solo e/ou da água subterrânea no município de Cuiabá, capital do Estado de Mato Grosso. O levantamento das áreas contaminadas foi feito por meio da análise documental dos processos de licenciamento ambiental dos postos de combustíveis existentes na Secretaria de Estado de Meio Ambiente (SEMA/MT). A necessidade do estudo realizado justifica-se pelo anseio de chamar a atenção para a importância de se inventariar essas áreas para que medidas adequadas possam ser tomadas. Além disso, é importante destacar que a atividade dos postos revendedores de combustíveis possui considerável potencial de contaminação das matrizes solo e água subterrânea, podendo restringir o uso de poços para abastecimento público instalados nas adjacências. 


\section{2. ÁREAS CONTAMINADAS}

Áreas contaminadas são descritas como locais com concentrações de poluentes representados por quaisquer substâncias ou resíduos que venham a causar danos ou riscos aos bens a proteger, como a qualidade das águas superficiais e subterrâneas, do solo e a saúde da população humana ou animal (CETESB, 2001). Geralmente, o surgimento de tais áreas está atrelado aos processos socioeconômicos ambientalmente não sustentáveis, que utilizam os recursos naturais sem observância aos parâmetros de proteção ambiental.

É importante ressaltar que áreas contaminadas e áreas degradadas não possuem o mesmo conceito. Áreas degradadas são locais que apresentam alterações negativas das suas propriedades físicas, tais como sua estrutura ou grau de compacidade, a perda de matéria devido à erosão e à alteração de características químicas, devido a processos como a salinização, lixiviação, deposição ácida e a introdução de poluentes. Áreas contaminadas são locais onde há comprovadamente poluição causada por quaisquer substâncias ou resíduos que tenham sido depositados, acumulados, armazenados, enterrados ou infiltrados, e que determina impactos negativos sobre os bens a proteger (CETESB, 2001). Sendo assim, as áreas contaminadas constituem um caso particular das áreas degradadas, e estão totalmente contidas nessas, ou seja, toda área contaminada é também uma área degradada (Günther, 2006).

Nos últimos anos, tem se observado uma ampla discussão entre os temas áreas contaminadas e áreas degradadas com o principal propósito de reintegrá-las à malha urbana. A necessidade de reutilização das áreas onde foram desenvolvidas atividades potencialmente poluidoras, como o caso de derramamento de combustíveis, tem se intensificado, sobretudo em regiões densamente povoadas e industrializadas. A sua reutilização de forma indiscriminada representa um grave aumento de risco à população como um todo e ao meio ambiente, pois podem funcionar como fontes dinâmicas de contaminação secundária, extrapolando os contaminantes para além da área afetada e para outros meios, estendendo seus efeitos deletérios (Günther, 2006).

O gerenciamento de áreas contaminadas visa minimizar os riscos que a população e o meio ambiente estão sujeitos, por meio de um conjunto de medidas que assegurem o conhecimento das características dessas áreas e dos impactos causados pelos contaminantes, proporcionando os instrumentos necessários à tomada de decisão quanto às formas de intervenção mais adequadas (CETESB, 2001). Os principais procedimentos e ações de investigação e de gestão durante esse processo devem seguir as seguintes etapas, segundo a Resolução CONAMA 420/2009 (Brasil, 2009): identificação, na qual uma avaliação preliminar e investigação confirmatória serão efetuadas; diagnóstico, que inclui a investigação detalhada e avaliação de risco com objetivo de subsidiar a etapa de intervenção; e intervenção, cuja finalidade é executar ações de controle para a eliminação do perigo ou redução a níveis toleráveis dos riscos, bem como o monitoramento da eficácia das ações executadas, considerando o uso atual e futuro da área. A Figura 1 apresenta detalhadamente estas etapas de gerenciamento de áreas contaminadas de acordo com o Anexo III da Resolução CONAMA 420/2009 (Brasil, 2009).

\subsection{Contaminação de solos e águas subterrâneas por derivados de petróleo}

Para se ter uma dimensão da problemática que envolve a contaminação do ambiente por hidrocarbonetos de petróleo, a Agência de Proteção Ambiental dos Estados Unidos (USEPA) estima que atualmente existam nesse país, aproximadamente, 571.000 tanques subterrâneos que armazenam derivados de petróleo e outras substâncias perigosas. Segundo o Programa de Tanques de Armazenagem Subterrâneos dessa agência, já foram registrados mais de 528.000 casos de vazamentos com consequente contaminação do solo e da água subterrânea sendo que 
aproximadamente 456.000 destas áreas contaminadas já foram recuperadas restando, portanto, 72.000 áreas em processo de remediação ou a ser remediada (USEPA, 2016).

Na Europa, a Agência Ambiental Europeia (European Environmental Agency - EEA) estima que aproximadamente 1.170 .000 áreas potencialmente contaminadas estão presentes em 27 países membros da EEA. A estimativa é que esse número representa $45 \%$ do total de áreas contaminadas presentes nos 39 países membros. O setor de serviços que mais contribui para essa contaminação são os postos de combustíveis com destaque principalmente em países como Holanda, Finlândia, Hungria, Croácia, Itália e Bélgica (EEA, 2014).

No Brasil, em meados de 1970, verificou-se um aumento nas instalações de postos de combustíveis. Nesta época os tanques de armazenamento de combustível eram construídos em chapa de aço simples, com uma vida útil de aproximadamente 20 a 25 anos. Após este período, muitos dos tanques não foram substituídos o que contribuiu para a ocorrência de vazamentos e contaminação ambiental (Oliveira e Loureiro, 1998).

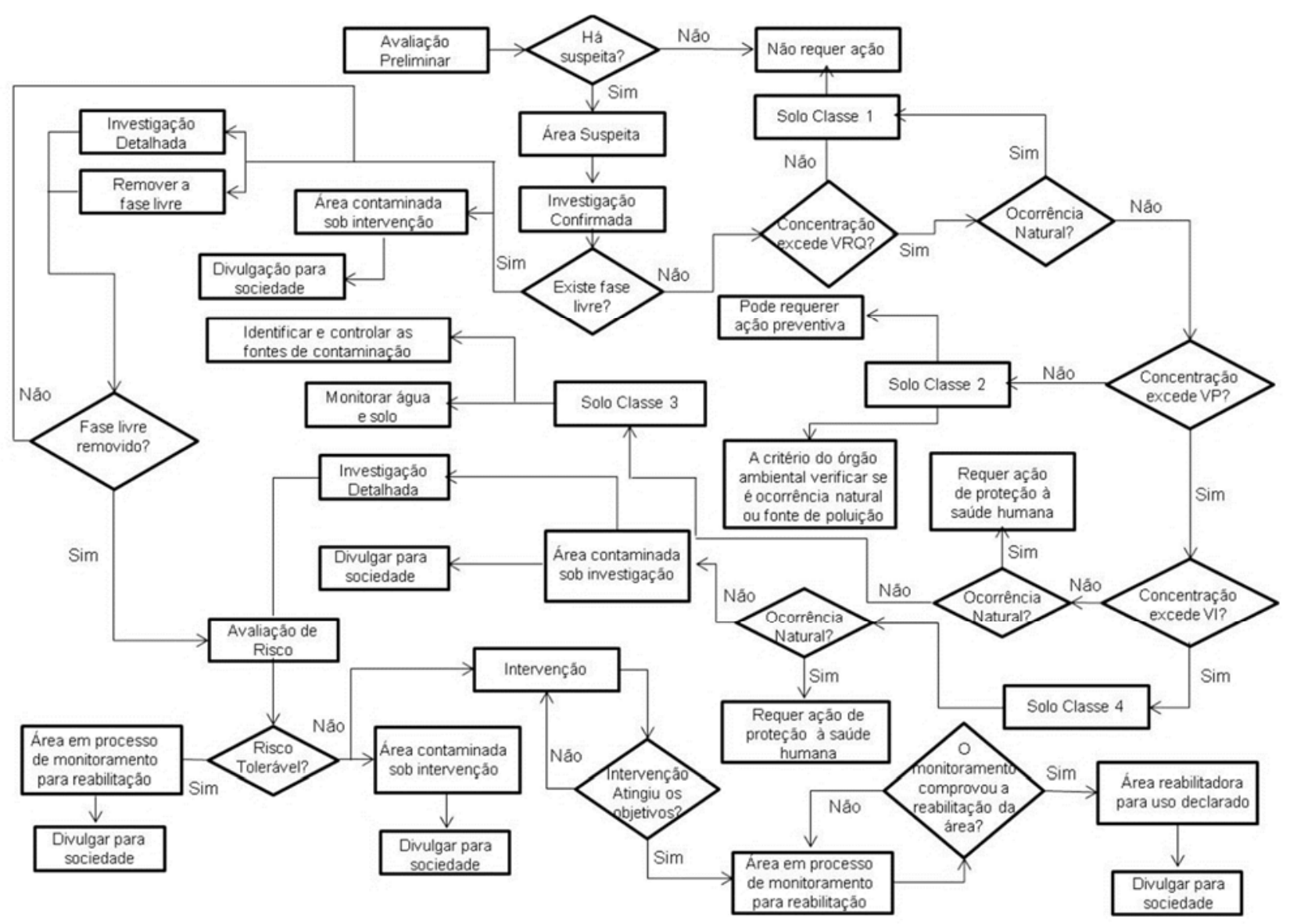

Figura 1. Fluxograma das etapas de gerenciamento de áreas contaminadas segundo a Resolução CONAMA 420/2009 (Brasil, 2009).

Quando há vazamentos de hidrocarbonetos em subsuperfície, estes podem se particionar em cinco fases distintas (CETESB, 2001):

1) Fase livre, quando existe produto puro em fase separada (imiscível ou parcialmente miscível) que apresenta mobilidade no meio poroso, podendo ser bombeado por fluir para o interior do poço; 
2) Fase residual, produto puro em fase separada (imiscível ou parcialmente miscível) que não apresenta mobilidade no meio poroso (não pode ser bombeado por não fluir para o interior do poço);

3) Fase vapor, quando o contaminante se encontra volatilizado, apresenta alta mobilidade, ocupando os espaços vazios existentes no solo, podendo acumular-se em espaços confinados como garagens subterrâneas, porões e utilidades (gás, telefonia, bueiros, entre outros);

4) Fase adsorvida, quando os contaminantes estão retidos nas partículas do solo por processos de adsorção, sobretudo em solos com alto teor de argila ou de matéria orgânica; e

5) Fase dissolvida, quando o contaminante se encontra dissolvido na água subterrânea, apresenta mobilidade muito elevada e é responsável pelo transporte do contaminante a grandes distâncias da fonte de contaminação.

O problema da contaminação de áreas adjacentes aos postos de combustíveis está relacionado com a difícil detecção do vazamento nos estágios iniciais. Diante dessa dificuldade, quando os efeitos da contaminação se tornam evidentes, o dano já pode ter atingido níveis alarmantes, assim, a saúde da população pode se encontrar em risco, e, em consequência disso, as ações remediadoras tornam-se urgentes (Silva, 2007).

Os compostos BTEX possuem alta solubilidade em água o que aumenta o risco de contaminação subterrânea (Anneser et al., 2008). A alta mobilidade desses compostos no sistema solo-água está relacionada com o baixo coeficiente de partição octanol-água, que conduz a uma baixa adsorção no solo favorecendo a contaminação das águas subterrâneas (Nakhla, 2003). Dessa forma, os compostos monoaromáticos do grupo BTEX encontrados nos combustíveis automotivos podem estar presentes dissolvidos na água subterrânea e podem restringir o uso de poços para abastecimento público instalados nas imediações de postos combustíveis que apresentam contaminações.

No Brasil, o etanol é adicionado à gasolina de acordo com a sua disponibilidade no mercado nacional. As diferentes formulações da gasolina/álcool podem influenciar o destino e transporte dos hidrocarbonetos, podendo assim, agravar a contaminação. Embora isso pudesse reduzir as emissões atmosféricas prejudiciais pelos automóveis, o problema da contaminação dos aquíferos é agravado, uma vez que o etanol pode exercer um efeito de cossolvente, aumentando a solubilidade do BTEX em água e, por conseguinte, resultando em concentrações mais elevadas e maiores prejuízos (Corseuil et al., 2011).

\subsection{Técnicas de remediação}

Uma vez constatada a contaminação de solos e águas, ações para a recuperação ambiental são necessárias para a proteção do ambiente e da saúde humana. Tal procedimento conhecido como remediação, implica em intervenção direta, com intuito de conter, isolar, remover ou reduzir as concentrações dos contaminantes presentes.

Diversas tecnologias para a remediação têm sido aplicadas em áreas contaminadas por derivados de petróleo. Dentre as que envolvem processos físicos e químicos podem ser citadas a lavagem de solo, extração de vapores, bombeamento e tratamento de águas subterrâneas, injeção de ar na zona saturada (air sparging), tratamento térmico, oxidação química, contenção e barreiras passivas e reativas. Também tem se destacado, devido ao menor custo e interferência mínima nas áreas contaminadas, as técnicas que removem o contaminante por meio de processos biológicos. Nesta categoria se destaca a atenuação natural, biorremediação e fitorremediação (Khan et al., 2004). A Tabela 1 apresenta breve descrição dessas principais técnicas de remediação. 
Tabela 1. Principais técnicas de remediação de áreas contaminadas.

Técnica Descrição

Lavagem de solo

Utiliza líquidos, geralmente água e solvente, e processos mecânicos para extrair os contaminantes do solo. Os solventes são escolhidos baseados na sua capacidade de solubilizar os contaminantes e não possuir ou ter baixa toxicidade.

Extração de vapores

É uma tecnologia que promove a remoção de compostos orgânicos voláteis (VOCs) da zona não saturada do solo por meio de aplicação de vácuo em poços próximos à fonte de contaminação.

Injeção de ar na zona

Aplicado na remediação de VOCs dissolvidos na água subterrânea e saturada (air sparging) adsorvidos na zona saturada do solo por meio da injeção de ar atmosférico sob pressão. Assim, ocorre a volatilização dos contaminantes em fase adsorvida e/ou biodegradação aeróbica.

Bombeamento e tratamento de águas subterrâneas

Por meio de poços de extração, as águas subterrâneas contaminadas são removidas e tratadas por diversas tecnologias. Uma vez remediadas são reintroduzidas no aquífero ou descartadas em corpos hídricos superficiais.

Tratamento térmico

Envolve o aquecimento do solo a temperaturas que variam de 100 a $600{ }^{\circ} \mathrm{C}$ com o objetivo de promover a separação dos contaminantes orgânicos pela volatilização ou destruição.

Oxidação química

Tratamento que utiliza oxidantes químicos como ozônio, peróxidos e persulfatos, para decompor, reduzir ou eliminar a toxicidade dos contaminantes em solos e águas subterrâneas.

Contenção

Consiste basicamente em criar barreiras físicas ou hidráulicas para impedir a dispersão dos contaminantes para áreas adjacentes.

Consistem na passagem da água subterrânea contaminada através de uma barreira permeável instalada em subsuperfície transversalmente ao sentido

Barreiras passivas e reativas de escoamento, interceptando a pluma de contaminação. Três tipos de barreiras são utilizadas: de adsorção, na qual os contaminantes ficam adsorvidos e são removidos; de precipitação, os contaminantes dissolvidos na água são precipitados e removidos; reativa, que promove a quebra dos compostos tóxicos em produtos inertes.

Atenuação natural controlada

Conhecida também como remediação intrínseca ou passiva, usa processos naturais que ocorrem na área contaminada com o objetivo de reduzir as concentrações dos contaminantes, toxicidade, massa e/ou volume até níveis adequados à proteção da saúde humana e ao meio ambiente.

Biorremediação

Por meio do metabolismo de microrganismos (bactérias e fungos), nativos ou exóticos à área contaminada, os contaminantes são degradados em compostos com menor ou sem toxicidade.

Fitorremediação

Plantas são utilizadas para remediar áreas contaminadas por meio da degradação, extração, contenção ou imobilização dos contaminantes orgânicos e inorgânicos do solo e água subterrânea.

Fonte: CETESB (2001) e Khan et al. (2004). 


\section{MATERIAL E MÉTODOS}

Neste trabalho, foram analisados os processos de licenciamento ambiental dos postos de combustíveis do município de Cuiabá, capital do Estado de Mato Grosso. Esta análise foi iniciada em março de 2014, com uma consulta ao banco de dados da SEMA/MT, denominado Sistema Integrado de Monitoramento e Licenciamento Ambiental (SIMLAM Público), e nesta etapa foi necessário o auxílio de um técnico da empresa responsável pela elaboração e manutenção do sistema, pois nem todas as informações estavam dispostas no site da SEMA/MT. O término das análises ocorreu em outubro de 2014.

A partir da avaliação do SIMLAM Público foram identificados 190 processos de licenciamento ambiental referentes a postos de combustíveis e em seguida uma análise documental desses processos foi efetuada, com auxílio dos técnicos da Coordenadoria de Serviços e do Setor de Arquivo da SEMA/MT. Dos 190 processos constantes do banco de dados digital, 136 foram encontrados no arquivo físico e analisados.

Assim, foi possível identificar os postos que já tiveram algum tipo de passivo ambiental oriundos de vazamentos em alguma parte do sistema de armazenamento subterrâneo ou até mesmo provenientes de derramamento de combustíveis no momento do abastecimento dos tanques e abastecimento dos veículos automotivos, tendo como consequência a contaminação do solo e/ou da água subterrânea. As informações extraídas da avaliação dos processos de licenciamento se basearam nas informações contidas nos relatórios de áreas contaminadas publicados pelos Estados de São Paulo e Minas Gerais, que já se encontram disponibilizados ao público de maneira geral. Dessa forma, foram pesquisadas as informações: postos de combustíveis com contaminação de hidrocarbonetos no solo e/ou na água subterrânea, fonte de contaminação, meios impactados, tipo de contaminantes presentes, presença de fase livre e técnica de remediação aplicada para eliminação, redução ou contenção da pluma de contaminação.

Um mapa com a localização dos postos de combustíveis no município de Cuiabá que apresentaram algum tipo de contaminação foi confeccionado utilizando o software ArcGis 10.2 com a base de dados geográficos da SEMA/MT, no qual foram adicionadas as coordenadas dos postos de combustíveis constantes nos processos analisados.

\section{RESULTADOS}

Após a análise de 136 processos de licenciamento ambiental de postos de combustíveis da cidade de Cuiabá, MT, Brasil, foram constatados que em 17 (12,6\%) processos, os laudos ambientais apresentaram concentrações de hidrocarbonetos que representam algum tipo de contaminação nas matrizes solo e/ou água subterrânea. Dezesseis desses postos com contaminação estão localizados na área urbana da capital, local com grande densidade domiciliar (Figura 2).

Os laudos ambientais também demonstraram que a água subterrânea foi atingida pela pluma de contaminação em $13(76 \%)$ postos de combustíveis e em três foram constatados a presença de fase livre (Tabela 2). As investigações das contaminações ocorreram entre os anos de 2005 a 2014, e os principais compostos avaliados foram os BTEX, hidrocarbonetos policíclicos aromáticos (HPA's) e compostos orgânicos voláteis (VOC).

Em quatro postos de combustíveis $(6,7,13$ e 15) foram detectadas emanações gasosas de compostos orgânicos voláteis (VOC) no solo, que variaram de 999 a 4.620 ppm (Tabela 2), porém, esses locais não foram submetidos a uma investigação detalhada para saber se 0 contaminante estava presente apenas na fase de vapor. Sabendo-se que um vazamento de derivados de petróleo geralmente se distribui em diversas fases (vapor, livre, residual, adsorvida 
e dissolvida), é necessário fazer análises nas matrizes solo e água subterrânea para saber a real distribuição dos contaminantes no ambiente.

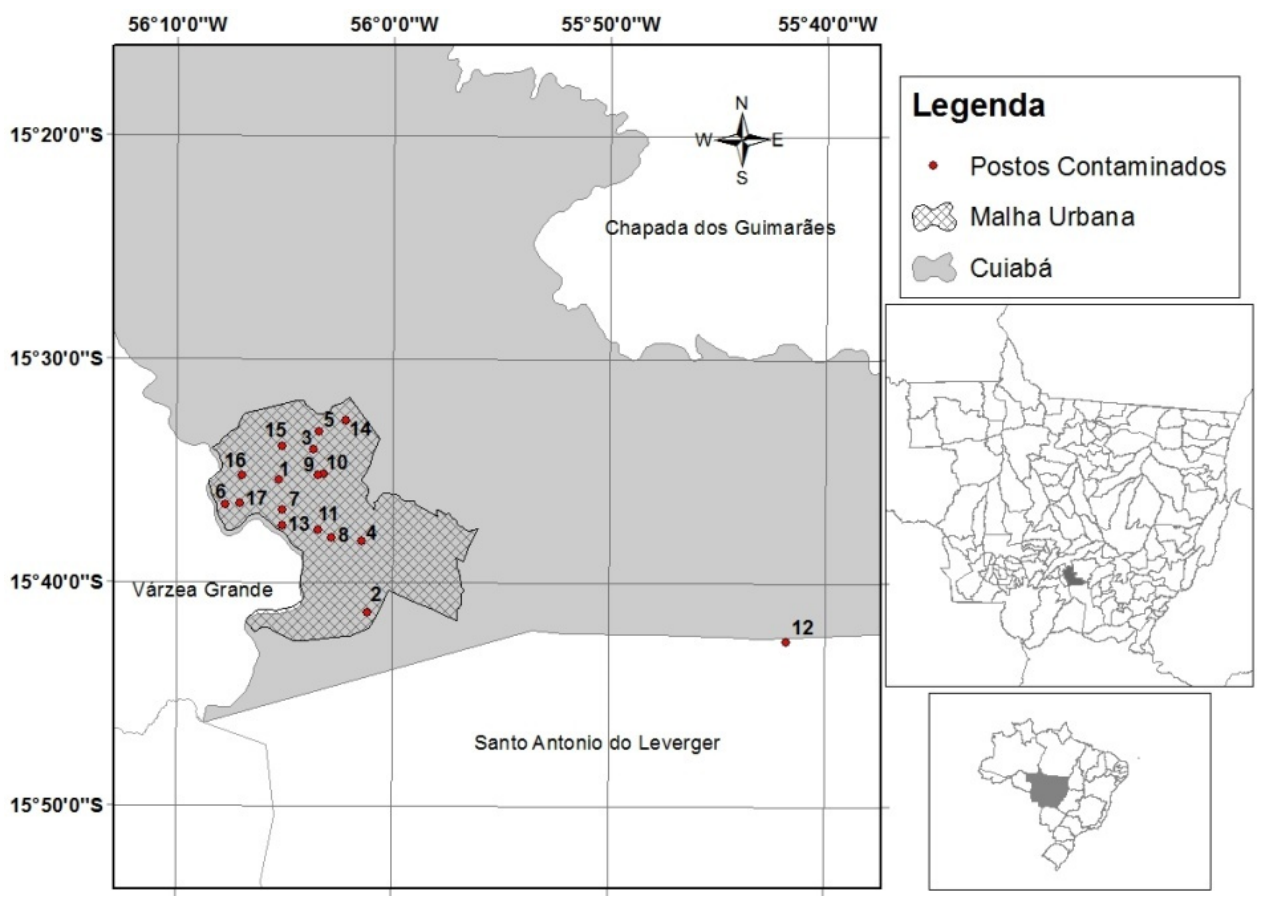

Figura 2. Localização dos postos de combustíveis com contaminação em Cuiabá, MT, Brasil.

Fonte: Organização dos autores.

Tabela 2. Características das contaminações dos postos de combustíveis no município de Cuiabá, MT, Brasil.

\begin{tabular}{cllcl}
\hline $\begin{array}{c}\text { Posto de } \\
\text { combustível }\end{array}$ & $\begin{array}{c}\text { Ano da } \\
\text { investigação }\end{array}$ & \multicolumn{1}{c}{ Meios impactados } & Fase livre & VOC (ppm) \\
\hline 1 & 2011 & Água Subterrânea e Solo & Não & $>10.000$ \\
2 & 2006 e 2011 & Água Subterrânea e Solo & Sim & $2006-$ até $7.280 /$ \\
3 & 2007 e 2010 & Água Subterrânea e Solo & Não & até 1.660 \\
4 & 2008 & Água Subterrânea e Solo & Não & até 11.000 \\
5 & 2006 e 2009 & Água Subterrânea e Solo & Sim $^{1}$ & até 11.000 \\
6 & 2011 & Solo & - & até 4.620 \\
7 & 2005 & Solo & - & até 4.400 \\
8 & 2009 & Água Subterrânea e Solo & Não & nd \\
9 & 2005 e 2006 & Água Subterrânea e Solo & Não & até 11.000 \\
10 & 2009 & Água Subterrânea & Não & nd \\
11 & 2009 e 2011 & Água Subterrânea & Sim & nd \\
12 & 2014 & Água Subterrânea & Não & nd \\
13 & 2006 & Solo & - & até 2.200 \\
14 & 2013 & Água Subterrânea & Não & nd \\
15 & 2009 e 2013 & Solo & - & até 999 \\
16 & 2013 & Água Subterrânea e Solo & Não & até 327 \\
17 & 2014 & Água Subterrânea e Solo & Não & até 360 \\
\hline
\end{tabular}

${ }^{1}$ Removida; nd $=$ não detectado. 
Os valores de BTEX e HPA's encontrados nos solos e águas subterrâneas adjacentes aos postos de combustíveis são apresentados nas Tabelas 3 e 4 . Destaca-se que em alguns processos de licenciamento (postos de combustíveis 2, 3 e 4) os valores individuais dos contaminantes não foram apresentados e sim o somatório de BTEX e HPA's (Tabela 5). Essa forma de apresentação dos resultados não é adequada, pois impede a comparação dos valores encontrados com aqueles orientadores estabelecidos pela CONAMA 420/2009 (Brasil, 2009).

Verificou-se ainda que nos processos de licenciamento ambiental dos postos 16 e 17 constam as informações da presença de contaminação e que análises dos passivos ambientais foram efetuadas em 2013 e 2014 respectivamente, porém não há documentos anexados referentes às quantidades de BTEX e HPA's encontrados nas matrizes solo e água subterrânea. Da mesma forma, para os postos 9 e 11 não foram apresentados os laudos da determinação desses poluentes nos processos, sendo encontrado somente a afirmação da contaminação.

Tabela 3. Concentração de BTEX e HPA's em solos adjacentes aos postos de combustíveis. As concentrações acima dos valores orientadores para solos residenciais estão destacadas em negrito.

\begin{tabular}{lccccccc}
\hline Posto de Combustível & 1 & 5 & 8 & 10 & 12 & 14 & $\begin{array}{c}\text { Valores } \\
\text { orientadores }\end{array}$ \\
\hline Benzeno & \multicolumn{7}{c}{ BTEXs $\left(\mathrm{mg} \mathrm{kg}^{-1}\right)$} \\
Etilbenzeno & nd & $\mathbf{8 , 2 3 9}$ & $\mathbf{0 , 1 0 2}$ & nd & nd & nd & 0,08 \\
Tolueno & 1,044 & 7,472 & 1,380 & nd & 0,0096 & nd & 40 \\
Xilenos & 0,021 & 13,572 & 0,501 & nd & nd & $<0,001$ & 30 \\
\hline & 6,58 & 24,5 & 11,854 & nd & nd & nd & 30 \\
\hline Acenafleno & 0,02 & 0,1186 & nd & nd & 0,028 & nd & $*$ \\
Acenaftileno & nd & 0,0777 & nd & nd & nd & nd & $*$ \\
Antraceno & nd & 0,0208 & nd & nd & $<0,010$ & nd & $*$ \\
Benzo(a)antraceno & nd & 0,0095 & nd & nd & nd & nd & 20 \\
Benzo(b)fluoranteno & nd & 0,0041 & nd & nd & nd & nd & $*$ \\
Benzo(k)fluoranteno & nd & 0,0018 & nd & nd & nd & nd & $*$ \\
Benzo(g,h,i)perileno & nd & nd & nd & nd & nd & nd & $*$ \\
Benzo(a)pireno & nd & 0,001 & nd & nd & nd & nd & 1,5 \\
Criseno & nd & 0,0457 & nd & nd & $<0,010$ & nd & $*$ \\
Dibenzo(a,h)antraceno & nd & nd & nd & nd & 0,070 & nd & 0,6 \\
Fenantreno & $<0,01$ & 1,153 & nd & nd & 0,151 & nd & 40 \\
Fluoranteno & nd & 0,0324 & nd & nd & nd & nd & $*$ \\
Fluoreno & $<0,01$ & 0,2597 & nd & nd & 0,062 & nd & $*$ \\
Indeno (1,2,3-c,d)pireno & nd & nd & nd & nd & nd & nd & 25 \\
Naftaleno & 2,56 & 14,384 & 0,1402 & nd & 0,070 & nd & 60 \\
Pireno & nd & 0,0619 & nd & nd & 0,014 & nd & $*$ \\
\hline Reslucac & & & & & \\
\hline
\end{tabular}

${ }^{1}$ Resolução CONAMA 420/2009 (Brasil, 2009).

nd $=$ não detectado.

*Valores não conformes aos estabelecidos pela Resolução CONAMA 420/2009 (Brasil, 2009). 
Tabela 4. Concentração de BTEX e HPA's em águas subterrâneas adjacentes aos postos de combustíveis. As concentrações acima dos valores orientadores estão destacadas em negrito.

\begin{tabular}{|c|c|c|c|c|c|c|c|}
\hline Posto de Combustível & 1 & 5 & 8 & 10 & 12 & 14 & $\begin{array}{c}\text { Valores } \\
\text { orientadores }^{1}\end{array}$ \\
\hline \multicolumn{8}{|c|}{ BTEXs $\left(\mu \mathrm{g} \mathrm{L}^{-1}\right)$} \\
\hline Benzeno & nd & 13246,5 & 1971,37 & 125,39 & 325,02 & 28,4 & 5 \\
\hline Etilbenzeno & 3112,9 & 1174,1 & 866,12 & 98,15 & 91,37 & nd & 300 \\
\hline Tolueno & 363,5 & 3902,5 & 3158,80 & 87,34 & nd & nd & 700 \\
\hline Xilenos & 13345 & 4562,9 & 5718,80 & 409,83 & 413,19 & nd & 500 \\
\hline \multicolumn{8}{|c|}{ HPA's $\left(\mu \mathrm{g} \mathrm{L}^{-1}\right)$} \\
\hline Acenafleno & $<1,5$ & 1,146 & 5,885 & 15,502 & 49,760 & nd & $*$ \\
\hline Acenaftileno & $<1,5$ & 0,337 & nd & 2,637 & nd & nd & $*$ \\
\hline Antraceno & $<1,5$ & 0,048 & nd & nd & 10,442 & nd & $*$ \\
\hline Benzo(a)antraceno & nd & nd & nd & nd & 4,005 & nd & 1,75 \\
\hline Benzo(b)fluoranteno & nd & nd & nd & nd & $<1,000$ & nd & $*$ \\
\hline Benzo(k)fluoranteno & nd & nd & nd & nd & $<1,000$ & nd & $*$ \\
\hline Benzo(g,h,i)perileno & nd & nd & nd & nd & $<1,000$ & nd & $*$ \\
\hline Benzo(a)pireno & nd & nd & nd & nd & $<1,000$ & nd & 0,7 \\
\hline Criseno & nd & 0,045 & nd & nd & 15,241 & nd & $*$ \\
\hline Dibenzo $(a, h)$ antraceno & nd & nd & nd & nd & nd & nd & 0,18 \\
\hline Fenantreno & $<1,5$ & 2,627 & nd & 7,357 & 180,642 & nd & 140 \\
\hline Fluoranteno & nd & 0,053 & 3,767 & 5,657 & 1,638 & nd & * \\
\hline Fluoreno & $<1,5$ & 1,656 & 4,348 & 11,379 & 79,084 & nd & $*$ \\
\hline $\begin{array}{l}\text { Indeno }(1,2,3-\mathrm{c}, \mathrm{d}) \\
\text { pireno }\end{array}$ & nd & nd & nd & nd & nd & nd & 0,17 \\
\hline Naftaleno & 106,95 & 344,967 & 430,639 & 204,961 & 294,798 & nd & 140 \\
\hline Pireno & nd & 0,101 & nd & nd & 18,207 & nd & $*$ \\
\hline
\end{tabular}

${ }^{1}$ Resolução CONAMA 420/2009 (Brasil, 2009).

nd $=$ não detectado.

*Valores não conformes aos estabelecidos pela Resolução CONAMA 420/2009 (Brasil, 2009).

Tabela 5. Somatório das concentrações de BTEX e HPA's encontrados nos solos e águas subterrâneas adjacentes aos postos de combustíveis 2,3 e 4.

\begin{tabular}{cccccc}
\hline \multirow{2}{*}{$\begin{array}{c}\text { Posto de } \\
\text { combustível }\end{array}$} & \multicolumn{2}{c}{ Água subterrânea $\left(\mu \mathrm{g} \mathrm{L}^{-1}\right)$} & & \multicolumn{2}{c}{ Solo $\left(\mathrm{mg} \mathrm{Kg}^{-1}\right)$} \\
\cline { 2 - 3 } \cline { 5 - 6 } & $\Sigma$ BTEX & $\Sigma$ HPA & & $\Sigma$ BTEX & $\Sigma$ HPA \\
\hline 2 & 81,9 & 6,15 & & nd & nd \\
3 & $997,0^{*} 996,282^{* *}$ & $90,856^{*} 13,320^{* *}$ & & $0,047^{*}$ & $0,3762^{*}$ \\
4 & 2727,8 & 386,872 & & 0,057 & 0,3620 \\
\hline
\end{tabular}

*ano de 2007; ** ano de 2009.

nd = não detectado. 
Outra informação importante para o gerenciamento das áreas contaminadas é em relação ao tipo de remediação que tem sido aplicada nessas áreas, sendo que em três casos a remediação tem ocorrido de forma natural e em nove casos não consta nos processos de licenciamento ambiental se algum tipo de remediação foi aplicado (Tabela 6). Vale destacar que a remediação natural é baseada na capacidade de atenuação natural dos contaminantes no solo e água subterrânea, e para ser considerada uma técnica efetiva de remediação é necessário um estudo criterioso da evolução da pluma de contaminação, uma metodologia de avaliação de risco e monitoramento durante todo o período necessário para que se atinjam as metas de remediação desejáveis (CETESB, 2001).

A técnica de bombeamento foi aplicada em três casos (Tabela 6). Esta técnica consiste em remover as águas contaminadas, por meio de poços de extração, para que ela seja tratada e reintroduzida no aquífero ou descartada em um corpo hídrico. Segundo São Paulo (CETESB, 2001), este é um dos métodos mais antigos de remediação e embora recentemente tenha sido substituído ou utilizado em combinação com outros métodos de remediação, ainda é largamente usado para remediar águas subterrâneas contaminadas em todo o mundo.

A técnica de extração multifásica (ventilação a vácuo) foi aplicada em três casos (Tabela 6). O sistema combina as técnicas de bioventilação e remoção de massa a vácuo, possibilitando a extração da fase livre, fase vapor, fase dissolvida na matriz do solo e estimulando o processo de biodegradação natural na zona não saturada (Khan et al., 2004).

Tabela 6. Técnicas de remediação aplicadas nas áreas contaminadas pelos postos de combustíveis em Cuiabá, MT, Brasil.

\begin{tabular}{|c|c|}
\hline Posto de Combustível & Técnica de Remediação \\
\hline 1 & Atenuação Natural \\
\hline 2 & Bombeamento \\
\hline 4 & $\begin{array}{l}\text { Bombeamento emergencial (água) e } \\
\text { Extração Multifásica (solo) }\end{array}$ \\
\hline 5 & Mini - Extração Multifásica \\
\hline 9 & $\begin{array}{l}\text { Extração Multifásica - sistema de } \\
\text { ventilação a vácuo }\end{array}$ \\
\hline 10 & Atenuação Natural \\
\hline 11 & Bombeamento \\
\hline 14 & Atenuação Natural \\
\hline $\begin{array}{l}3,6,7,8,12,13,15 \\
16 \text { e } 17\end{array}$ & $\begin{array}{l}\text { Nenhuma informação encontrada sobre a } \\
\text { aplicação de técnicas de remediação }\end{array}$ \\
\hline
\end{tabular}

\section{DISCUSSÃO}

Os principais poluentes orgânicos liberados durante um vazamento em tanques de armazenamento subterrâneo em postos de combustíveis são representados principalmente por diesel e gasolina. Tais combustíveis são constituídos principalmente por HPA's, BTEX e hidrocarbonetos alifáticos. O benzeno é o composto mais tóxico dentre os BTEX devido a suas características tóxicas e carcinogênicas mesmo em concentrações da ordem de

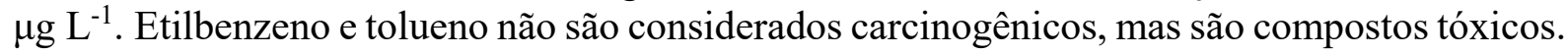
Xilenos são misturas de três isômeros (orto, meta e para-xileno) e possuem dois grupos metil 
ligados ao anel benzênico. Apesar de serem menos perigos que os outros BTEX eles podem causar doenças do fígado, rins e sistema nervoso (Rosales et al., 2014).

De acordo com a Portaria do Ministério da Saúde n 2.914/2011 (Brasil, 2011), o benzeno possui padrão de potabilidade de $5 \mu \mathrm{g} \mathrm{L}^{-1}$. Já os demais compostos, tolueno, etilbenzeno e xilenos são regulados com concentração máxima permitida em águas subterrâneas, de 170, 200 e $300 \mu \mathrm{g} \mathrm{L} \mathrm{L}^{-1}$, respectivamente, quando o uso preponderante é o consumo humano, segundo a Resolução CONAMA 396/2008 (Brasil, 2008).

Alguns passivos ambientais nos postos de combustíveis apresentaram valores de BTEX em água subterrânea acima do preconizado por essas legislações (Tabela 4). Valores acima dos valores orientadores estabelecidos pela Resolução CONAMA 420/2009 (Brasil, 2009) também foram encontrados principalmente para águas subterrâneas (Tabelas 3 e 4). Este fator passa a ser relevante para a distribuição das ameaças ao meio ambiente, pois a contaminação pode atingir um elevado número de pessoas quando esta atinge as águas subterrâneas. Tal fato pode se tornar ainda mais crítico em Cuiabá devido às condições de intermitência no abastecimento de água em muitos bairros, principalmente aqueles localizados na periferia, o que levam os moradores a construir poços rasos para a captação de água do nível freático, ou seja, água que está mais sujeita a contaminação.

A constatação de que técnicas de remediação não foram aplicadas em $53 \%$ dos postos que apresentaram contaminação pode ser considerada alarmante. No gerenciamento de áreas contaminadas, a remediação é uma das ações que possibilitam a mitigação dos impactos ambientais para a contínua ocupação e reocupação dessas áreas por meio da minimização e controle dos riscos, sendo uma etapa obrigatória segundo a Resolução CONAMA 420/2009 (Brasil, 2009). E mesmo nos casos em que as técnicas remediadoras foram aplicadas nas áreas contaminadas, informações referentes ao monitoramento posterior à remediação não foram encontradas nos processos. Entretanto, segundo os técnicos da Coordenadoria de Serviços e do Setor de Arquivo da SEMA/MT, documentos com estas informações podem não ter sido anexados aos mesmos.

A seleção e implementação de técnicas de remediação de áreas contaminadas no Brasil ainda é uma atividade que necessita de desenvolvimento na maioria dos estados. Segundo Cunha (2014), apesar do grande número de empresas de consultoria na área de investigação e remediação de áreas contaminadas, o país ainda carece de profissionais com capacitação técnica e científica o que acaba levando a ações de investigações mal planejadas e executadas e ineficiência dos sistemas de remediação. Prova disso é o fato da técnica de bombeamento e tratamento estar relacionada como a mais utilizada segundo dados disponibilizados pela Cetesb (2014) no Estado de São Paulo, ainda que sua ineficiência para promover a remediação de áreas contaminadas tenha sido relatada pelo National Research Council, nos EUA, na década de 1990 (Cunha, 2014).

Conforme relatado anteriormente, a SEMA/MT não possui uma publicação com as informações das áreas contaminadas do Estado de Mato Grosso, incluindo as áreas contaminadas por hidrocarbonetos de petróleo, o que pode dificultar o eficiente gerenciamento dessas áreas. Vale lembrar que a Resolução CONAMA 420/2009 (2009) no seu artigo 38, aponta que os órgãos ambientais competentes, deverão dar publicidade às informações sobre áreas contaminadas identificadas e suas principais características, na forma de um relatório.

Alguns estados brasileiros têm avançado no sentido de estabelecer legislações específicas para regulamentar essa matéria. Orientações das ações dos responsáveis pela contaminação assim como a atuação de profissionais técnicos tem sido encontrada na Lei Estadual $n^{\circ}$ 13.577/2009 em São Paulo (São Paulo, 2009), na Deliberação Normativa Conjunta COPAM/CERH n ${ }^{\circ}$ 02/2010 em Minas Gerais (Minas Gerais, 2010), na Portaria FEPAM ${ }^{\circ}$ 49/2014 no Rio Grande do Sul (Rio Grande do Sul, 2014) e na Resolução CONEMA nº 44/2012 no Rio de Janeiro (Rio de Janeiro, 2012). Além disso, também é importante a definição de 
padrões e valores orientadores levando em consideração as particularidades de cada Estado para que o gerenciamento de áreas contaminadas possa ser desenvolvido de forma adequada.

Este trabalho abordou apenas as áreas que foram contaminadas por derivados de petróleo em postos de combustíveis no município de Cuiabá, o que aponta a necessidade de avaliar os outros 140 municípios do Estado. Entretanto, não somente a atividade comercializadora de combustíveis automotivos deve ser considerada, pois Mato Grosso é um Estado com destaque para a agropecuária e mineração, atividades que também possuem potencial de contaminar o meio ambiente. Alguns trabalhos, inclusive, já demonstraram a contaminação de águas superficiais e subterrâneas do Estado por pesticidas (Cassara et al., 2012; Nogueira et al., 2012; Ribeiro et al., 2013), mercúrio (Vieira e Alho, 2004) e cromo (Cunha e Shiraiwa, 2011) destacando a necessidade de ampliar as investigações das áreas contaminadas.

\section{CONCLUSÕES}

O gerenciamento de áreas contaminadas configura um grande desafio ambiental para órgãos reguladores, empreendedores e sociedade em geral, considerando que o uso dessas áreas pode conferir riscos à saúde humana. Neste trabalho, um panorama dos postos de combustíveis responsáveis por algum tipo de contaminação ambiental em Cuiabá, MT, Brasil, foi apresentado. A identificação das contaminações foi efetuada por meio da análise dos processos de licenciamento ambiental dos postos de combustíveis que se mostrou uma ferramenta importante, já que a investigação de passivos ambientais é uma das etapas do processo do licenciamento. Foram identificados 17 postos com algum tipo de contaminação no solo e/ou água subterrânea, sendo os contaminantes BTEX, hidrocarbonetos policíclicos aromáticos e compostos orgânicos voláteis os principais poluentes encontrados nesses locais, como era de se esperar devido à natureza da atividade desenvolvida. Alguns passivos ambientais nos postos de combustíveis apresentaram valores de BTEX nas águas subterrâneas acima do preconizado pelas legislações brasileiras. O número de postos com passivo ambiental pode ser maior que os 17 encontrados, pois 54 processos de licenciamento não foram encontrados nos arquivos da Secretaria de Estado de Meio Ambiente (SEMA/MT). Em apenas nove processos foram encontradas informações sobre a aplicação de técnicas de remediação sendo elas: bombeamento, extração multifásica e atenuação natural. A SEMA/MT não apresenta uma compilação das informações dessas áreas contaminadas na forma de um relatório conforme indicado na Resolução CONAMA 420/2009, o que poderia facilitar o gerenciamento das mesmas. O desenvolvimento de políticas pelo Estado de Mato Grosso relativas à gestão das áreas contaminadas com legislações específicas ao tema se mostra necessário e irá nortear o efetivo gerenciamento das áreas contaminadas.

\section{AGRADECIMENTOS}

À Secretaria de Estado de Meio Ambiente (SEMA/MT), pela atenção e disposição dos dados referentes a essa pesquisa. À CAPES pela concessão de bolsa de estudos de mestrado.

\section{REFERÊNCIAS}

ANDRADE, J. A.; AUGUSTO, F.; JARDIM I. C. S. F. Biorremediação de solos contaminados por petróleo e seus derivados. Eclética Química, v. 35, n. 3, p. 17-43, 2010. http://dx.doi.org/10.1590/S0100-46702010000300002

Rev. Ambient. Água vol. 12 n. 2 Taubaté - Mar. / Apr. 2017 
ANNESER, B.; EINSIEDL, F.; MECKENSTOCK, R. U.; RICHTERS, L.; WISOTZKY, F.; GRIEBLER, C. High-resolution monitoring of biogeochemical gradients in a tar oilcontaminated aquifer. Applied Geochemistry, v. 23, n. 6, p. 1715-1730, 2008. http://dx.doi.org/10.1016/j.apgeochem.2008.02.003

AGÊNCIA NACIONAL DE PETRÓLEO, GÁS NATURAL E BIOCOMBUSTÍVEIS - ANP (Brasil). Anuário estatístico brasileiro do petróleo, gás natural e biocombustíveis 2015. Rio de Janeiro, 2015.

BRASIL. Ministério do Meio Ambiente. Conselho Nacional do Meio Ambiente. Resolução no 273, de 29 de novembro de 2000. Brasília, 2000.

BRASIL. Ministério do Meio Ambiente. Conselho Nacional do Meio Ambiente. Resolução no 396, de 03 de abril de 2008. Brasília, 2008.

BRASIL. Ministério do Meio Ambiente. Conselho Nacional do Meio Ambiente. Resolução no 420, de 28 de dezembro de 2009. Brasília, 2009.

BRASIL. Ministério da Saúde. Portaria no 2.914 de 12 de dezembro de 2011. Brasília, 2011.

CASARA, K. P.; VECCHIATO, A. B.; LOURENCETTI, C.; PINTO, A. A.; DORES, E. F. G. C. Environmental dynamics of pesticides in the drainage area of the S??o Louren??o River headwaters, Mato Grosso State, Brazil. Journal of the Brazilian Chemical Society. v.23, n.9, p.1719-1731, 2012. http://dx.doi.org/10.1590/S0103-50532012005000037

COMPANHIA AMBIENTAL DO ESTADO DE SÃO PAULO - CETESB. Relação de áreas contaminadas e reabilitadas no Estado de São Paulo. São Paulo, 2014, 14 p.

COMPANHIA AMBIENTAL DO ESTADO DE SÃO PAULO - CETESB. Manual de gerenciamento de áreas contaminadas. 2001. Disponível em: http://areascontaminadas.cetesb.sp.gov.br/manual-de-gerenciamento/. Acesso em: 02 maio 2016

CORSEUIL, H. X.; MONIER, A. L.; FERNANDES, M.; SCHNEIDER, M. R.; NUNES, C.C.; DO ROSARIO, M. et al. BTEX plume dynamics following an ethanol blend release: geochemical footprint and thermodynamic constraints on natural attenuation. Environmental Science and Technology, v. 45, n. 8, p. 3422-3429, 2011. http://dx.doi.org/10.1021/es104055q

CUNHA, R. C. A. Prefácio. In: MORAES, S. L.; TEIXEIRA, C. E.; MAXIMIANO, A. M. S. (Org.). Guia de elaboração de planos de intervenção para o gerenciamento de áreas contaminadas. São Paulo: IPT, 2014. p. 5-7.

CUNHA, L. F. J.; SHIRAIWA, S. Aplicação do método eletromagnético indutivo na investigação da pluma de contaminação da água subterrânea por resíduos de cromo de curtume. Revista Brasileira de Geofísica, v.29, n.1, p.127-134, 2011. http://dx.doi.org/10.1590/S0102-261X2011000100009

EUROPEAN ENVIRONMENT AGENCY - EEA. Progress in the management of Contaminated Sites in Europe. Ispra: Institute for Environment and Sustainability, 2014, $72 \mathrm{p}$.

GÜNTHER, W. M. R Áreas contaminadas no contexto da gestão urbana. São Paulo em Perspectiva, v. 20, n. 2, p. 105-117, 2006. 
KHAN, F. I.; HUSAIN, T.; HEJAZI, R. An overview and analysis of site remediation technologies. Journal of Environmental Management, v. 71, n. 2, p. 95-122, 2004. http://dx.doi.org/10.1016/j.jenvman.2004.02.003

MINAS GERAIS. Deliberação Normativa Conjunta COPAM/CERH nº 02, de 08 de setembro de 2010. Institui o Programa Estadual de Gestão de Áreas Contaminadas, que estabelece as diretrizes e procedimentos para a proteção da qualidade do solo e gerenciamento ambiental de áreas contaminadas por substâncias químicas. Diário do Executivo - Minas Gerais, Belo Horizonte, 2010.

MINAS GERAIS. Fundação Estadual do Meio Ambiente. Inventário de áreas contaminadas do Estado de Minas Gerais - 2015. Belo Horizonte, 2015. 45 p.

NAKHLA, G. Biokinetic modeling of in situ bioremediation of BTX compounds - impact of process variable and scaleup implications. Water Research, v. 37, n. 6, p. 1296-1307, 2003. http://dx.doi.org/10.1016/S0043-1354(02)00491-8

NOGUEIRA, E. N.; DORES, E. F. G. C., PINTO, A. A.; AMORIM, R. S. S.; RIBEIRO, M. L.; LOURENCETTI, C. Currently used pesticides in water matrices in central-western Brazil. Journal of the Brazilian Chemical Society. v. 23, n. 8, p. 1476-1487, 2012. http://dx.doi.org/10.1590/S0103-50532012005000008

OLIVEIRA, L. I.; LOUREIRO, C. O. Contaminação de aquíferos por combustíveis orgânicos em Belo Horizonte: avaliação preliminar. In: CONGRESSO BRASILEIRO DE ÁGUAS SUBTERRÂNEAS, 10., 1998, São Paulo. Anais... São Paulo: Associação Brasileira de Águas Subterrâneas, 1998.

RIBEIRO, A. C. A.; DORES, E. F. G. C.; AMORIM, R. S. S.; LOURENCETTI, C. Resíduos de pesticidas em águas superficiais de área de nascente do rio São Lourenço-MT: validação de método por extração em fase sólida e cromatografia líquida. Química Nova. v. 36, n. 2, p. 284-290, 2013. http://dx.doi.org/10.1590/S0100-40422013000200015

RIO DE JANEIRO. Resolução CONEMA no 44, de 14 de dezembro de 2012. Diário Oficial do Estado do Rio de Janeiro, Rio de Janeiro, 2012.

RIO DE JANEIRO. Instituto Estadual do Ambiente. Gerenciamento de áreas contaminadas do Estado do Rio de Janeiro. 3. ed. Rio de Janeiro, 2015.

RIO GRANDE DO SUL. Fundação Estadual de Proteção Ambiental Henrique Luiz Roessler. Portaria FEPAM no 49 de 28 de maio de 2014. Porto Alegre: Secretaria do Meio Ambiente, 2014.

ROSALES, R. M.; MARTÍNEZ-PAGÁN, P.; FAZ, A.; BECH, J. Study of subsoil in former petrol stations in SE of Spain: Physicochemical characterization and hydrocarbon contamination assessment. Journal of Geochemical Exploration, v. 147, p. 306-320, 2014. http://dx.doi.org/10.1016/j.gexplo.2014.10.006

SÃO PAULO. Lei $\mathrm{n}^{\circ} 13.577$, de 8 de julho de 2009. Dispõe sobre diretrizes e procedimentos para a proteção da qualidade do solo e gerenciamento de áreas contaminadas, e dá outras providências correlatas. Diário Oficial do Estado, São Paulo, Seção I, 9 jul. 2009. p.1-3 
SILVA, F. G. Gestão de áreas contaminadas e conflitos ambientais: o caso da cidade dos Meninos. 2007. 110 f. Dissertação (Mestrado em Ciências em Planejamento Energético) - Instituto Alberto Luiz Coimbra de Pós-Graduação e Pesquisa de Engenharia, Universidade Federal do Rio de Janeiro, Rio de Janeiro, 2007.

UNITED STATES. Environmental Protection Agency - USEPA. Cleaning Up Underground Storage Tank (UST) Releases. Disponível em: https://goo.gl/WBj6DY. Acesso em: 16 maio 2016.

VIEIRA, L. M.; ALHO, C. J. R. Contaminação por mercúrio em sedimento e moluscos da bacia do rio Bento Gomes, MT. Corumbá: Embrapa Pantanal, 2004. 20p. 